ORNL/TM-12658

Dist. Category UC -420

Fusion Energy Division

\title{
ITER ECH LAUNCHER OPTIONS FOR START-UP ASSIST, BULK-HEATING, AND EC CURRENT DRIVE EXPERIMENTS
}

\author{
T. S. Bigelow \\ Date Published: March 1994 \\ Prepared for the U. S. Department of Energy \\ Office of Fusion Energy \\ Budget Activity 150403 A
}

\author{
Prepared by \\ OAK RIDGE NATIONAL LABORATORY \\ Oak Ridge, Tennessee 37831-6285 \\ managed by \\ MARTIN MARIETTA ENERGY SYSTEMS, INC. \\ for the \\ U.S. DEPARTMENT OF ENERGY \\ under contract DE-AC05-84OR21400
}


This report was prepared as an account of work sponsored by an agency of the United States Government. Neither the United Sates Government nor any agency thereof, nor any of their employees, makes any warranty, express or implied, or assumes any legal liability or responsibility for the accuracy, completeness, or usefulness of any information, apparatus, product, or process disclosed, or represents that its use would not infringe privately owned rights. Reference herein to any specific commercial product, process, or service by trade name, trademark, manufacturer, or otherwise does not necessarily constitute or imply its endorsement, recommendation, or favoring by the United States Government or any agency thereof. The views and opinions of authors expressed herein do not necessarily state or reflect those of the United Sates Government or any agency thereof. 
CONTENTS

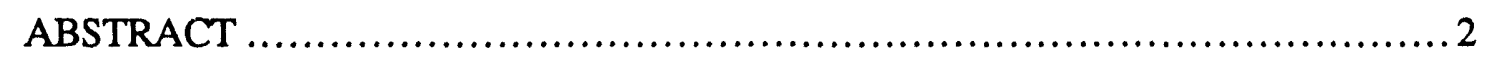

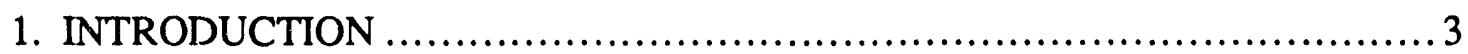

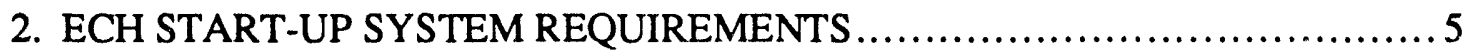

3. ECH BULK HEATING SYSTEM REQUIREMENTS .........................6

4. EC CURRENT DRIVE REQUIREMENTS .................................. 7

5. POWER GENERATION AND TRANSMISSION SYSTEMS $\ldots \ldots \ldots \ldots \ldots \ldots \ldots \ldots 8$

6. START-UP AND HEATING LAUNCHER CONFIGURATIONS ............... 10

7. LAUNCHER SURVIVABILITY IN THE ITER ENVIRONMENT $\ldots \ldots \ldots \ldots \ldots \ldots$

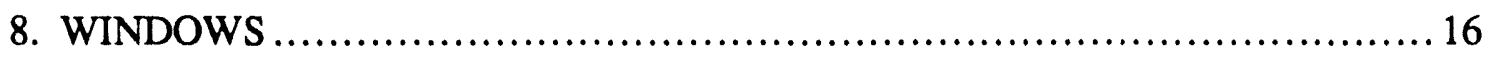

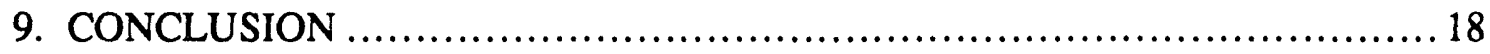

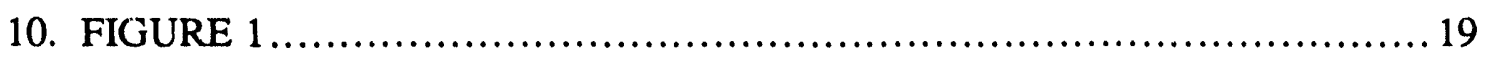

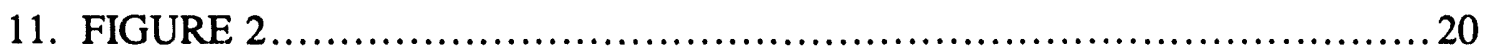

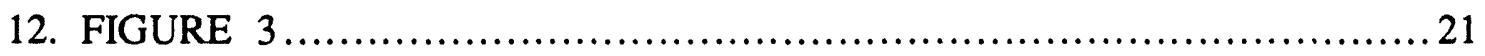

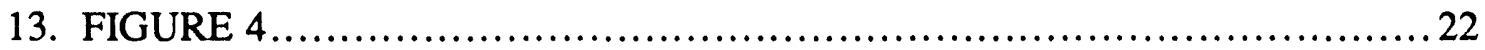

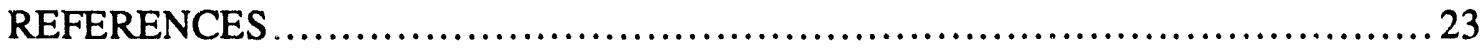




\begin{abstract}
Electron Cyclotron Heating (ECH) is proposed for providing plasma start-up, bulk heating, current drive, and other applications on the International Tokamak Experimental Reactor (ITER) project. The requirements for ECH power launching systems for ITER have been investigated, and several possible configurations that have been devised are described in this report. The proposed launcher designs use oversized circular corrugated waveguides that make small penetrations through the blanket modules and radiate into the plasma. The criteria used for the design calls for minimum blanket penetration area, maximum reliability, and optimum launched beam quality. The effects of the harsh plasma edge environment on the launcher are discussed. Power generation systems, windows, and other components of the ECH systems are also investigated. The designs presented are believed to be capable of operating reliably and are relatively easy to maintain remotely.
\end{abstract}




\section{INTRODUCTION}

Electron Cyclotron Heating (ECH) is heing considered for plasma start-up assistance, bulk plasma heating, and several other applications on International Thermonuclear Experimental Reactor (ITER). One of the primary advantages of ECH heating systems is the potential for compact, high-power-density launchers that are simple, reliable, and rugged. These advantages were lost in the ECH launcher design proposed during the ITER Conceptual Design Activity (CDA). The CDA configuration was primarily designed for the mission of plasma disruption suppression, which requires localized current drive at the moving $q=2$ surface. This was to be accomplished by scanning the toroidal angle of the launched beam, which results in an extremely large launcher design that requires a large port opening. The CDA ECH system design, although elegant and well prepared, has apparently been abandoned due to its large port, reflector size, a reduced ITER program emphasis on disruption suppression, and redesign of the ITER concept. Because there are significant benefits in using ECH on ITER, alternative applications to the CDA system are being promoted. Several applications, when evaluated from both a physics and overall system perspective, appear to have significant merit, especially when the launcher is kept simple because this reduces the overall system cost and increases its reliability and desirability to the ITER project. Additional features, such as beam steering capability, can increase the capabilities of ECH systems; however, any feature will have to be reviewed by the ITER project team to determine if the additional launcher complication is warranted. At this point, it is assumed for a baseline system that no moving parts are allowed inside the ITER vacuum boundary, and only a minimum launcher area penetrating the blanket will be acceptable.

Plasma start-up assistance is a good application for ECH because it is capable of ionizing gas and providing heating to a localized region fairly independently of temperature and density as the plasma evolves. Due to superb launcher characteristics, ECH is also ideal for bulk plasma heating on ITER. The power can be deposited in a highly localized region and delivered through very small penetrations in the blanket from a launcher that is quite reliable, very rugged against disruptions and neutrons, and also easily retractable for maintenance if necessary. There is also interest in performing electron cyclotron current drive (ECCD) on ITER. Use of a fixed-angle launcher, which can drive current at a fixed major radius, is being considered. Other applications for $\mathrm{ECH}$ power include a transport diagnostic using power modulation, a plasma edge heating tool for confinement improvement, an alpha particle diagnostic using wave scattering, and a vessel wall conditioning system using continuous low-density plasma formation.

Design of an ECH power launching system for a reactor project such as the ITER requires careful integration with the vacuum vessel and shielding/blanket modules designs. Although there is still some uncertainty on the actual blanket module configuration, enough is known to begin to 
incorporate systems that must penetrate through it, such as ECH launchers. This report describes the launcher requirements and possible configurations for several ECH applications on ITER. In some instances, it is possible to combine several functions into one set of launchers; this will increase system flexibility and reduce costs. If the transmission system is properly designed, different ECH frequencies could be injected from one launcher at different times by using waveguide switches to select different gyrotrons.

The launcher designs presented are sets of corrugated waveguide apertures that penetrate the ITER blanket modules. Corsugated wavegrides are broadband and launch gaussian-like beam patterns that are ideally polarized. The power density through the blanket penetrations can be as high as $600 \mathrm{MW} / \mathrm{m}^{2}$. This configuration is quite simple and provides the greatest reliability with very little loss of flexibility. This approach will be the least objectionable to blanket and system integration designers, while still providing most of the capabilities desired from the ECH system.

ECH power generation and transmission systems for ITER have been discussed previously $1-3$ and are only reviewed briefly as required for these applications. The availability of $1-\mathrm{MW} \mathrm{cw}$ gyrotron tubes and barrier windows for heating at $168 \mathrm{GHz}$ and current drive at $\sim 200 \mathrm{GHz}$ is still a major impediment to the immediate construction of practical $50-\mathrm{MW}$ heating systems, and development work should continue in this area. 


\section{ECH START-UP SYSTEM REQUIREMENTS}

Plasma start-up is a principal application of ECH for ITER because it can provide significant performance improvement at modest cost. The physics of plasma start-up is rather involved and has not been modeled self-consistently with all transport, equilibrium, and atomic physics effects included. However, a preliminary model of the ECH plasma start-up assist process, which indicates that there is a significant reduction in required ohmic heating volt-seconds with modest amounts of power, has been implemented by Nevins. ${ }^{4}$ The model predicts that only $2 \mathrm{MW}$ of absorbed ECH power applied at start-up is sufficient to reduce loop volt-second requirements by a factor of 3 or more, depending on the maximum loop voltage allowed. ECH will also provide more consistent plasma start-up because the breakdown location and time are precisely controlled. Nevin's model is based on power balance of the ohmic plus ECH power combined with dominant plasma loss mechanisms including the effects of beryllium impurities. The start-up scenario used in the model is provided by Wesley; 5 it specifies that the plasma breakdown should occur near the outer limiter on the toroidal coil midplane where a null in net the magnetic field is located. The formation of the plasma near a limiter minimizes its size and radiated power level to avoid radiative collapse. As shown in Fig. 1, the plasma increases in size, and the axis is moved inward and upward until it reaches the nominal configuration after $\sim 40 \mathrm{~s}$. The ECH start-up power is required for only a short time period (probably $<2$ s) until sufficient plasma current is built up to provide adequate confinement and the ohmic power can sustain the plasma.

The plasma start-up analysis of Nevins and Wesley 4,5 indicates that an absorbed ECH power level of $\sim 2 \mathrm{MW}$ for $2 \mathrm{~s}$ is required. Because the first-pass absorption in the low-density, low-temperature start-up plasma is low, additional power and/or a beam refocusing system may be required. A more accurate power deposition analysis is required to quantify the total power needed. The magnetic field at the outboard start-up location is $\sim 4.8 \mathrm{~T}$, so an ECH frequency of 130 to $140 \mathrm{GHz}$ is required for heating at this location. Starting the plasma off-axis requires a lower frequency gyrotron system than necessary for central heating. Of course, if adequate ECH power were installed to sustain a full-size start-up plasma under low current, poor-confinement conditions, the plasma could be started up centered on the normal axis, and the same ECH system could function for start-up and heating. Additional analysis of the start-up physics would be useful to understand the power requirements for on-axis plasma start-up. 


\section{ECH BULK HEATING SYSTEM REQUIREMENTS}

The simplicity and high-power density of waveguide launchers make $\mathrm{ECH}$ quite attractive for bulk plasma heating on ITER. A grouping of corrugated waveguide launchers $<100 \mathrm{~mm}$ in diameter aimed at the plasma axis will provide very centralized power deposition in the plasma. The auxiliary heating power level required for plasma ignition on ITER is $\sim 50 \mathrm{MW}$ in most recent discussions on the subject. An ECH frequency of $\sim 168 \mathrm{GHz}$ is required for heating at the $6 \mathrm{~T}$ central field location. The pulse length requirement for auxiliary heating is $40 \mathrm{~s}$ or longer. The plasma density during bulk heating could be as high as $3 \times 10^{20} \mathrm{~m}^{-3}$ on axis, which is sufficiently below the O-mode cutoff density of $3.3 \times 10^{20} \mathrm{~m}^{-3}$ for $168-\mathrm{GHz}$ penetration. 


\section{EC CURRENT DRIVE REQUIREMENTS}

Plasma current drive using electron cyclotron waves (ECCD) requires oblique toroidal launch angle and is most efficient when launched from the low magnetic field side in the frequency upshifted resonance condition. An upshift of $\omega=1.3 \omega_{c}$ and a toroidal angle of $\sim 30^{\circ}$ provide close to the optimum ECCD conditions. An ECH frequency of $\sim 200 \mathrm{GHz}$ is required for current drive at the plasma center. Off-axis current drive or central current drive at reduced magnetic field could be accomplished with an installed $168-\mathrm{GHz}$ ECH system if the toroidal launch angle can be adjusted or multiple launchers selectable with waveguide switches are installed. 


\section{POWER GENERATION AND TRANSMISSION SYSTEMS}

Start-up assist using ECH at the outboard limiter location requires 130 to $140 \mathrm{GHz}$ power with a pulse length of $2 \mathrm{~s}$ or longer. The available power level required must be higher than specified by the physics requirements to allow for transmission and plasma losses. Gyrotrons with $\mathrm{cw}$ capability in the 130 to $140-\mathrm{GHz}$ range are not quite available at the $1-\mathrm{MW}$ level although $500-\mathrm{KW}$ tubes are quite realistic at this time. Medium pulse length $(\sim 1 \mathrm{~s}) 1-\mathrm{MW}$ tubes at $140 \mathrm{GHz}$ are now available and have been used on plasma heating experiments. Based on past progress in gyrotron development, it is likely that $140-\mathrm{GHz}, 1-\mathrm{MW}$ or higher-power cw tubes will be available long before ITER is operational, provided gyrotron development programs continue to be supported. Between two and four gyrotrons with transmission lines and launchers will be required to deposit $2 \mathrm{MW}$ in the plasma for start-up. If the pulse length is limited to 1 to $2 \mathrm{~s}$, inertially cooling gyrotron collectors and windows allow higher power tube operation; however, there would be large thermal cycling of these components. Tube reliability is greatly increased when thermal excursions are minimized, so actively cooled cw-type tubes are preferred.

Heating the full-size plasma on axis with $\mathrm{ECH}$ requires $\sim 168 \mathrm{GHz}$ power. An auxiliary heating system for ITER is generally assumed to have a power capability of $50 \mathrm{MW}$. EC current drive on axis is also assumed to be practical at up to $50 \mathrm{MW}$ and will require $200-\mathrm{GHz}$ power. Gyrotrons at these higher frequencies will be more difficult to build than $140-\mathrm{GHz}$ tubes and will require more development work. The barrier windows will also be more difficult because window dielectric losses increase with frequency. If the unit power has to be dropped significantly below $1 \mathrm{MW}, \mathrm{ECH}$ for bulk heating and current drive becomes less attractive due to the large number of gyrotron and transmission systems that would be required. A higher unit power, such as 2 to $3 \mathrm{MW}$ per tube, would allow significant savings in overall system costs because the transmission line, launcher, and power supply subsystems are essentially identical for either power level, and fewer systems would be required at the higher unit power level. With the successful development of windows and higher power tubes, $\mathrm{ECH}$ will be quite attractive for bulk heating on ITER.

The gyrotron systems will be located well away from the tokamak in a shielded vault, ${ }^{2}$ and an individual transmission system will be required for each gyrotron because power combination of incoherent sources is not really practical. For frequencies below $\sim 200 \mathrm{GHz}$, circular corrugated waveguide with a diameter of 35 to $90 \mathrm{~mm}$ is ideal for transporting the power from the gyrotron vault to the tokamak in the low-loss, linearly polarized $\mathrm{HE}_{11}$ mode. The choice of the optimum waveguide diameter is a complicated trade-off between several factors related to power density and mode conversion loss. 6 Simple miter bends are broadband and quite efficient provided the 
waveguide diameter is sufficiently large. Miter bend mode-converstion loss is proportional to $\mathrm{D}^{-3 / 2}$, where $\mathrm{D}$ is the diameter. However, waveguide straightness becomes more critical as the diameter increases to maintain acceptable levels of mode conversion. Mode conversion due to curvature is proportional to $(D / R)^{2}$, where $R$ is the bend radius of curvature $(R=\infty$ for straight waveguide). However, waveguide stiffness also increases $\sim D^{2}$, which keeps the need for bracing and supports approximately independent of diameter. Waveguide power density and electric field levels are proportional to $\mathrm{D}^{-2}$ and $\mathrm{D}^{-1}$, respectively. Therefore, reliability against breakdown due to sharp corners and dust particles is greatly improved with larger diameters, and power loading at bend mirrors is also greatly reduced. For these reasons, the larger diameters $(88.9 \mathrm{~mm}$ is frequently chosen) are preferred and are likely to be selected for the final design. High-power systems using various diameters will be tested in the next few years. Corrugated waveguide manufacturing has been demonstrated to be practical in sections $3 \mathrm{~m}$ long (or possibly longer) at Oak Ridge National Laboratory (ORNL) using a large thread cutting-tap arrangement.

The waveguide system will require several additional components ${ }^{6}$ such as directional couplers for power monitoring, waveguide switches, dummy loads, vacuum pumpout sections, dc breaks, valves, and windows. Many of these components have been designed and tested under nearly ITER-relevant conditions, although more extensive system tests will be required before the final design can be completed. Evacuated waveguide operation is preferred for several reasons, although low-pressure gas fill is an option. Total transmission system efficiency is likely to be $>85 \%$ including all losses.

A redundant waveguide window system is required for each waveguide near the tokamak to provide vacuum isolation and radioactive particle containment. The windows will be located around several bends away from the line of sight of the plasma to reduce the neutron and gamma flux degradation to the window ceramic. ${ }^{2}$ Several possible window designs are currently being investigated for this type application; however, it may be a few years until a 160 to $200-\mathrm{GHz}$, 1-MW cw capable window with demonstrated reliability is available. The edge-cooled, pulse window may be capable of 1 to 2-s operation although reliability is questionable due to the large temperature excursions. Further discussion on window requirements is included in a later section. 


\section{START-UP AND HEATING LAUNCHER CONFIGURATIONS}

For plasma start-up at the outboard limiter location on the toroidal field coil midplane, the ECH power must be launched toward this spot as shown in Figs. 1 and 2. These two possible launc ar configurations are optimized for outboard plasma start-up and are relevant to recent ITER vacuum vessel and blanket design data. The design philosophy has specified that no moving parts be permitted inside the vacuum vessel, and the absolute minimum of blanket penetration area is allowed. Maintenance requirements and system alignment operations should be minimized. The launcher configuration shown in Fig. 1 is a set of corrugated waveguides with inside diameters of $<90 \mathrm{~mm}$ that are angled downward to point directly at the start-up location. In Fig. 2, the waveguide is routed, using miter bends, through a gap in the blanket to a launch point located below midplane. There are pros and cons associated with either launcher arrangement. Figure 1 style of waveguides and associated cooling systems can likely be made directly retractable for repair or replacement with minimum access requirements inside the vessel and no removal of blanket modules. There will be lower neutron and neutral particle flux directly on plasma facing mirror surfaces because the first miter bend mirror is a long way from the plasma. These waveguides must pass through small holes in the blanket modules that are potentially a problem for the blanket design. The holes would typically be $100 \mathrm{~mm}$ in diameter. A sectioned blanket with a split slightly below midplane would work. Cooling can easily be maintained in the split blanket by running cooling lines above and below the waveguides and out through the vacuum vessel.

With the configuration shown in Fig. 2, the waveguides are more difficult to retract from the vessel in one step; however, there is more flexibility on launch angle and beam focusing because the miter bends allow waveguide axis rotation, and parabolic focusing mirrors can be used as the last bend. This configuration does not require penetrations through blanket modules (which are split into upper and lower halves in this case) and also allows one type of launcher to serve for both start-up and central heating, because the same launch direction passes through the start-up and central heating location. A toroidal angle for current drive applications can be provided by rotation of the last miter bend. This rotation angle can be changed occasionally by inserting an actuator at maintenance times and making tilt adjustments. If a full-time remote pointing control is deemed reliable enough, a permanent actuator using vacuum feedthroughs could be installed, giving the system more launch flexibility.

Figure 3 shows a simple launcher configuration optimized for centralized heating. This arrangement is similar to Fig. 1 where the waveguides penetrate straight through the blanket/shielding modules and can be retracted and inserted straight through the vacuum vessel port for easy maintenance. A set of miter bends could be used just behind the blanket module to 
provide beam focusing if desired, although it is not clear that this is really necessary on ITER. There is a potential problem with plasma-facing mirrors located close to the plasma due to neutral particle sputtering.

Some level of waveguide cooling will be required due to reflector resistivity losses and power deposition from neutrons and neutral particles, especially at plasma-facing miter bends. The cooling lines should be an integral part of the waveguide assembly to simplify repair and maintenance or replacement.

For the highest system efficiency, first-pass absorption must be maximized, otherwise power will bounce around the vacuum system, and only a fraction of the launch power will be deposited in the desired loration. Despite the metallic reflecting walls, there are many sinks for high-frequency ECH power in the large vacuum vessel. The resonance layer in the tokarnak covers a much larger region of the plasma than the desired start-up volume, and there are many large holes such as divertors, vacuum pumping ducts, and surface scale buildup due to sputtering. High first-pass absorption requires a narrow launch beam of proper polarization directed toward the resonance location. The launch beam pattern from the corrugated waveguide carrying the $\mathrm{HE}_{11}$ gaussian-like mode is a gaussian beam with low sidelobes. Any polarization (assuming the vacuum window is polarization "agile") is possible using universal polarizers located far away in the gyrotron area. In most cases, only one particular polarization needs to be launched, namely, horizontal linear polarization for O-mode absorption at the fundamental resonance location with propagation perpendicular to $B_{0}$.

An unfocused radiated gaussian beam waist size (1/e field point) increases in free space away from the waveguide aperture according to $w(z) / w_{0}=\left[1+\left(\lambda z / \pi w_{0}^{2}\right)^{2}\right]^{1 / 2}$. Examples of beam waist vs distance along the beam are shown in Fig. 4 for several cases of different aperture size and frequency and in one case, with focusing. Focusing can decrease the beam width approximately inversely proportional to the increase in the mirror aperture size. Diffraction due to plasma density gradients will cause some additional beam spread, although at these high frequencies, very high plasma densities are required to cause significant spread. Beam-ray tracing analysis has been performed by Smith ${ }^{7}$ for a high-density case $\left(n_{\mathrm{emax}}=3 \times 10^{20} \mathrm{~m}^{-3}\right)$ relevant to heating for the two different launch points. At this high density, the beam width is approximately doubled by plasma diffraction. It appears that except for very small waveguide sizes, the unfocused corrugated waveguide radiator is quite adequate for plasma startup and heating applications in ITER due the very large plasma size relative to beam width. At a distance of 3000 $\mathrm{mm}$ the beam width has only doubled $170-\mathrm{GHz}$ beam generated in a $90-\mathrm{mm}$ aperture (waist size $\sim 28 \mathrm{~mm}$ ).

For electron cyclotron (EC) current drive, a slight toroidal angle of $\sim 30^{\circ}$ and a downshifted frequency is required for optimum efficiency. A frequency of $\sim 200 \mathrm{GHz}$ is required for centralized 
current drive. The launcher configurations shown in Figs. 2 and 3 can provide the toroidal angle tilt where the final miter bend is a parabolic-ellipsoidal mirror with launch angle adjustment capability. The penetration area through the blanket will have to be elongated for the launcher in Fig. 3 if toroidal steering is to be implemented. Toroidal tilt of the beam also requires an elliptical launch polarization for optimum absorption of the beam. The polarization can be adjusted outside the vacuum region with a universal polarizer ${ }^{2}$ provided the window is polarization insensitive. 


\section{LAUNCHER SURVIVABILITY IN THE ITER ENVIRONMENT}

One of the key issues in the ECH launcher design for ITER is survivability. The plasma edge environment in ITER is extremely harsh for any materials due to the high neutron and neutral particle flux and high-power deposition. There are also potentially very large forces induced in plasma edge structures due to plasma disruptions. Fortunately, the simple launcher designs presented in this report are quite rugged and well suited to the application. The launchers are well recessed and contain no dielectric materials except at the window location, which is well removed from direct neutron flux.

Material problems that exist near the plasma edge include erosion due to neutral particle sputtering, swelling due to atomic displacements from neutron collisions, and stresses from plasma disruption forces. Other potential problems include streaming neutron effects on the window dielectric and high-power deposition from the plasma. Some of the incident power fluxes for the plasma edge that could be determined from available literature are summarized in Table 1 along with the approximate power deposition in a mirror placed at the plasma edge. ${ }^{1}$ More information or calculations of these values is desirable for further refining this design.

Table 1. Power flux and power deposition in edge mounted mirror.

\begin{tabular}{|c|c|c|}
\hline Flux type & Incident power /flux & Power deposition \\
\hline ECH power & $15-60 \mathrm{KW} / \mathrm{cm}^{2}$ & 70 to $300 \mathrm{~W} / \mathrm{cm}^{2}$ \\
\hline Fast neutron flux & $10^{14}$ neutron $/ \mathrm{cm}^{2} / \mathrm{s}$ & \\
& $250 \mathrm{w} / \mathrm{cm}^{2}$ & \\
\hline Thermal neutrons & & $<100 \mathrm{~W} / \mathrm{cm}^{2}$ \\
\hline Plasma radiation & $<100 \mathrm{~W} / \mathrm{cm}^{2}$ & $<1 \mathrm{~W} / \mathrm{cm}^{2}$ \\
\hline Neutral particles (50-100 ev) & $10^{16} \mathrm{part} / \mathrm{cm}^{2} / \mathrm{s}$ & Low \\
\hline Gamma radiation & & Low \\
\hline Alpha and beta particles & & \\
\hline
\end{tabular}

In the launcher options shown in Figs. 1 and 3, an open-end, corrugated, circular waveguide penetrates through the blanket and points at the plasma. The waveguide walls at the aperture would be directly exposed to nearly the plasma edge flux values shown in Table 1 . Because the last miter bend mirror is quite distant from the plasma in this scheme, the neutron and particle flux are greatly reduced due to the small plasma solid angle visible from the mirror surface. 
The waveguide aperture region will be subject to sputtering, heating, and disruption forces. Along the entire vacuum region length, the waveguide will also be required to operate at $300^{\circ} \mathrm{C}$ to maintain good vacuum conditioning. Material choice for waveguide in the edge region should be based on maximum lifetime, mininum nuclear activation, adequate electrical conductivity, and minimum plasma impurity generation. Conductivity for corrugated waveguide walls, where the $\mathrm{HE}_{11}$ mode is propagating, is less critical than for reflectors where the surface current is much higher. Sputtering will remove and redeposit thin layers in direct sight of the plasma, so metal plating is not desirable. Disruption forces can be overcome by reacting the resulting axial torque and radial force on the waveguide to the blanket sections with mechanical interlocks.

Aluminum, beryllium, tungsten and copper alloys have been suggested for microwave reflector materials ${ }^{1}$ and could also be used for waveguide. Aluminum and beryllium have good conductivity and are low $\mathrm{Z}$ but will be more subject to sputtering. High $\mathrm{Z}$ metals such as tungsten have the lowest sputtering coefficients but are highly activated by neutrons. A higher resistivity material will experience smaller disruption forces. A waveguide section constructed from carbon composites could function adequately and would have minimum disruption forces.

If the waveguide corrugation grooves close to the plasma gather dust particles from the vacuum vessel, periodic cleaning will be required to maintain the best mode purity and launcher beam pattern and reduce the chance of arcing. This could be accomplished during maintenance periods using a remotely operated vacuum cleaner. A hole in the bottom of each corrugation groove could allow small particles to eventually vibrate out if there is sufficient vibration of the machine (ITER may be very quiet except during disruptions).

In the launcher design in Fig. 2, the last miter bend is located quite close to the plasma, and sputtering of the mirror surface may become an issue. Excessive, non uniform sputtering can lead to beam distortion and increased resistive losses. A high-conductivity material is required to minimize resistive losses, so copper is preferred. Tungsten has been suggested as a highconductivity mirror surface with low sputtering coefficient; however, it is quite brittle and is high $\mathrm{Z}$. Beryllium could be used for the reflector surface and has excellent conductivity, low activation, and low $Z$. However, it is more subject to sputtering. An analysis of the sputtering rate is required to determine which material has an acceptable lifetime.

The first mirror and waveguide sections near the plasma will require significant cooling for the power deposited from the plasma. Power deposition in these components can be removed using cooling techniques similar to those being developed for the blanket modules such as helium gas, liquid metal, and high-pressure water. High-temperature, high-pressure water cooling is probably the preferred option. The high temperature provides constant surface vacuum conditioning. Cooling lines could be incorporated into the waveguide assembly as reliable single loops of tubing for the designs presented in Figs. 1 and 3 because these assemblies can be inserted 
as one piece into the vacuum vessel. When in-vessel assembly of waveguide sections is required, the cooling-water lines may require joints that will reduce reliability and require welding or brazing operations. 


\section{WINDOWS}

The barrier window is a key component of the launcher subsystem and is effectively where the launcher subsystem ends and the transmission line subsystem begins. A window is required for tritium and radioactive particle containment as well as vacuum isolation. Because it is a primary containment structure, a safety back-up window must be included in case of window breakage. ${ }^{1}$ It is likely that the transmission system will also be evacuated so vacuum will exist on both sides of the window during normal operation.

The ideal window would transmit any polarization, operate over a wide frequency range, and handie $1 \mathrm{MW} \mathrm{cw}$ at the highest frequency of interest. The bandwidth requirement could be relaxed because the windows can be changed out if the gyrotron frequency is changed, especially if a waveguide vacuum valve is placed between the window and the vacuum vessel. Polarization capability is desirable, although if launch angle is fixed or only adjusted over a small angle range near perpendicular, a single linear polarization is acceptable. Adjustment of polarization inside the vacuum is less desirable, because cooled moving mirrors would be required in the vacuum region. Placing these mirrors in well shielded regions could provide acceptable reliability.

Adequate window designs for $1-\mathrm{MW} \mathrm{cw}$ at this frequency range have not been demonstrated although several options are being investigated, such as cryogenic single-disk edge-cooled or double-disk, face-cooled; double-elongated disk room-temperature designs; and distributed room-temperature designs. All window designs that are proposed in the near term are based on high-purity sapphire dielectrics; however, high-purity, single-disk diamond or aluminum nitride windows are a possibility in the near future as manufacturing techniques for these materials improve.

An additional difficulty added by the ITER environment is that the window must operate exposed to some neutron and gamma irradiation. The window can be located in a well-shielded region around several bends to reduce the flux. The residual flux that reaches the window location is primarily streaming neutrons that travel straight down the waveguide and bounce (scatter) off the miter bend mirror surfaces. There are also small quantities of "guided" neutrons that scatter off waveguide walls and possibly neutrons that penetrate the shielding. Any neutron flux reaching the window location will have been thermalized by the scattering, and associated gamma flux will accompany the neutrons. The flux at the window location can be approximated from the plasma edge flux by the ratio of solid angle of the plasma at the waveguide opening to the solid angle of the plasma at the window and factoring in the attenuation of the bends. Each bend provides a factor of $\sim 10$ attenuation ${ }^{2}$ and the solid angle factor is 0.003 for $10 \mathrm{~m}$ of 90 -mm-diam waveguide. A factor of $3 \times 10^{-6}$ attenuation at the window location seems likely. This implies that the flux 
through the window will be $3 \times 10^{8}$ neutrons $/ \mathrm{cm}^{2} \mathrm{~s}$, and a total fluence will be $8 \times 10^{15}$ neutrons $/ \mathrm{cm}^{2}$ after $8000 \mathrm{~h}$ of operation (1 full year burn). Due to the good shielding offered by this launcher configuration, this is a relatively low flux and is not likely to produce a significant increase in window material properties. A more accurate calculation of this neutron flux and the portion that is absorbed by the window material is desired soon for this configuration of launcher. More detailed measurements on loss tangent of sapphire (and possibly diamond) with relevant neutron bombardment is desirable and quite practical and should be performed soon using a similar cavity measurement scheme as used at RF frequencies. ${ }^{8}$ 


\section{CONCLUSION}

Several possible ECH launcher configurations are proposed for the ITER device. They are designed to have minimum complexity, minimum blanket penetration area, high reliability, and permit most of the possible ECH applications. Many of the critical design issues have been outlined. The physics requirements must be finalized and additional analysis of these launcher schemes performed to determine if they fulfill enough of the requirements. Careful design integration work with the blanket design is necessary, so that the launcher has minimal impact on the blanket but allows sufficient maintainability of the launcher. A detailed engineering analysis of the launcher survivability using detailed data on the ITER environment must be performed, including neutron and particle flux analysis, disruption force analysis, and material selection. The window portion of the launcher is one of the more difficult components to design at this time. Although well shielded, the window design chosen should also be analyzed for neutron effects using data from dielectric loss tangent measurements under neutron bombardment. The relative simplicity and robustness of these proposed launcher schemes appears to be sufficiently improved over the earlier CDA design that they should greatly assist in establishing acceptance of ECH on ITER and allow completion of the launcher design relatively quickly. 


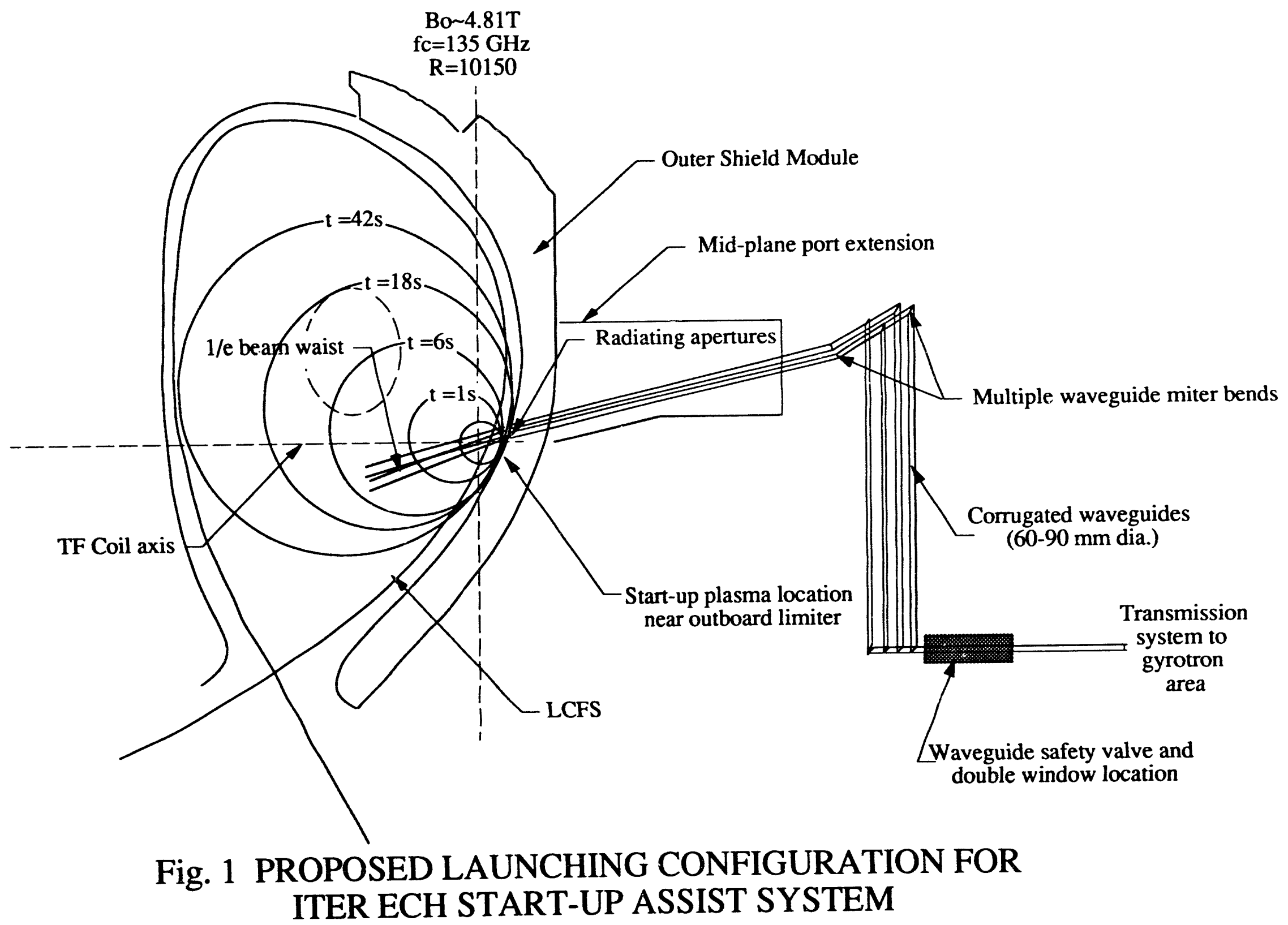

4 waveguides shown for 2- $4 \mathrm{MW}$ power launched 


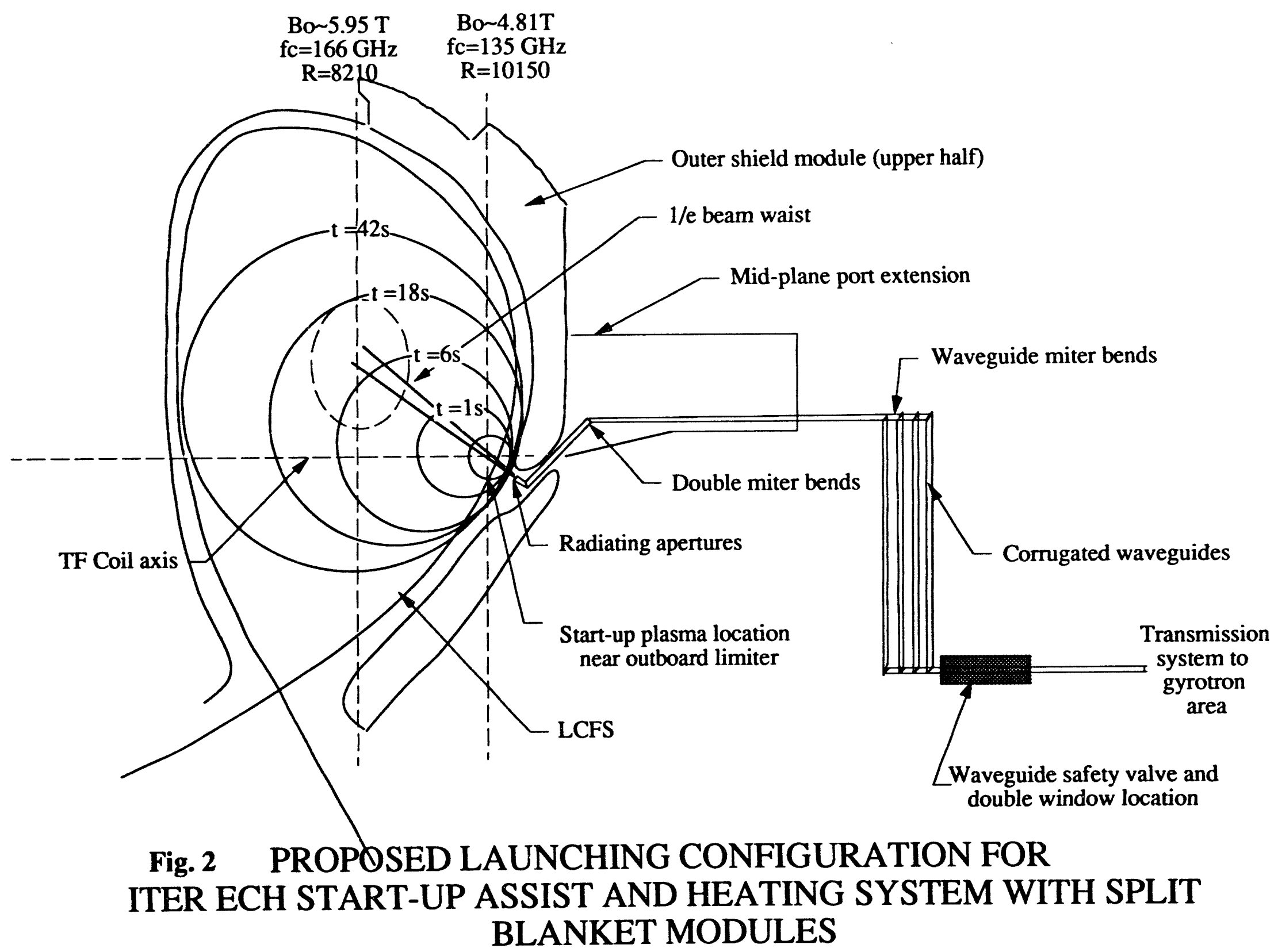




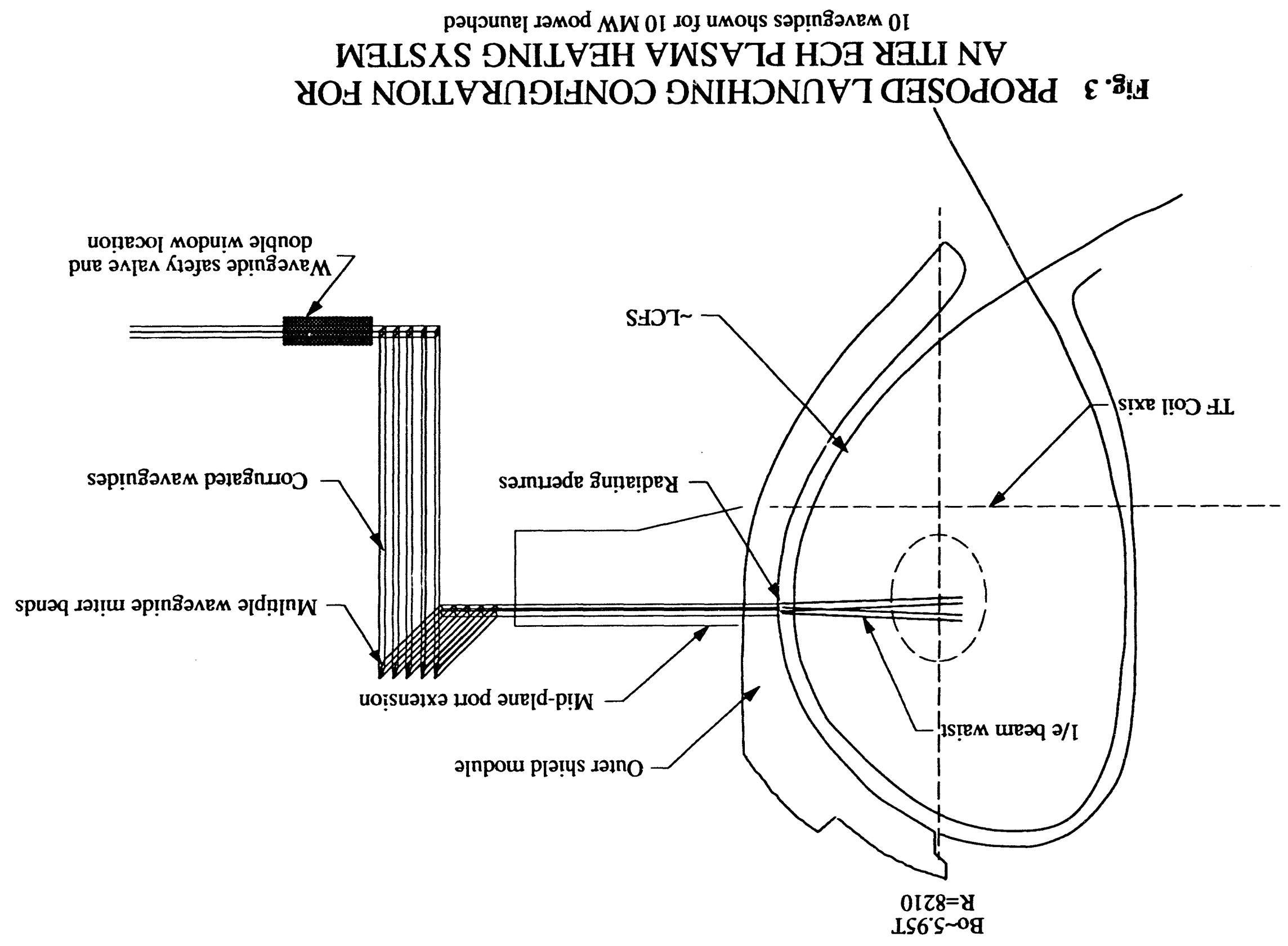




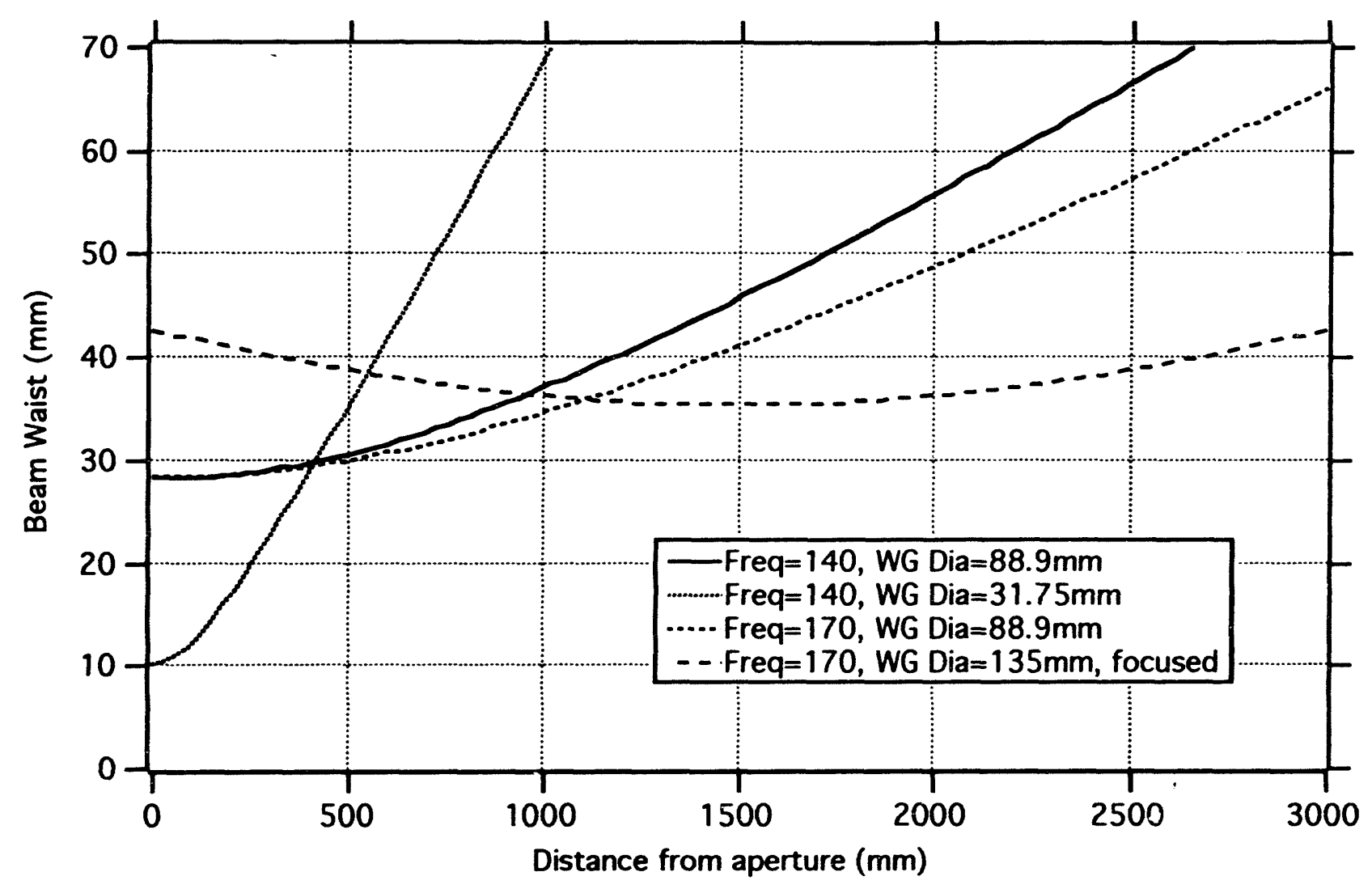

Fig. 4 GAUSSIAN BEAM DIFFRACTION FOR SEVERAL WAVEGUIDE SIZES AND FREQUENCIES 


\section{REFERENCES}

1. L. Rebuffi et al., ITER Electron Cyclotron Wave System Common Conceptual Design, ITER-IL-HD-6-0-31, 1991.

2. T. S. Bigelow, D. W. Swain, and M. Sawan, 1993 Proceedings RF Heating of Plasmas, AIP Conf. Digest.

3. D. W. Lang, and W. Lindquist, Start-up system presentation to ITER JCT, January 1993.

4. W. M. Nevins, "Power Requirements for Electron Cyclotron Start-up Assist," memo dated May 13, 1993.

5. J. Wesley, "Plasma Magnetics and Energy Balance for ITER Start-up," ITER JCT Memo, April 24, 1993.

6. W. Helne et al., Study on ECW Transmission Lines for NET/ITER, EUR-FU/80/90-99, October 1990.

7. G. R. Smith, private communication with T. S. Bigelow, June 1993.

8. R. E. Stoller, R. H. Goulding, and S. J. Zinkle, " Measurement of dielectric properties in ceramics under ionizing and displacive irradiation conditions," L_ Nuc. Matl. 191-194 (1992). 602-606. 


\section{ORNL/TM-12658 \\ Dist. Category UC-420}

\section{INTERNAL DISTRIBUTION}

1. C. C. Baker

2. D. B. Batchelor

3. G. L. Bell

4-8. T. S. Bigelow

9. R. J. Colchin

10. B. A. Carreras

11. M. D. Carter

12. R. A. Dory

13. R. H. Goulding

14. G. R. Hanson

15. D. J. Hoffman

16. D. C. Lousteau

17. S. L. Milora

18. D. A. Rasmussen
19. D. W. Swain

20. T. E. Shannon

21. W. L. Stirling

22. N. A. Uckan

23. J. Sheffield

24. Laboratory Records Department - RC

25-26. Laboratory Records Department

27. Central Research Library

28. Document Reference Section

29. Fusion Energy Division Library

30-31. Engineering Technology/Fusion Energy Division Publications Office

32. ORNL Patent Section

\section{EXTERNAL DISTRIBUTION}

33. Office of the Assistant Manager for Energy Research and Development, Department of Energy Field Office, Oak Ridge, P.O. Box 2000, Oak Ridge, TN 37831

34. D. E. Baldwin, Lawrence Livermore National Laboratory, P.O. Box 5511, Livermore, CA 94550

35. J. D. Callen, Department of Nuclear Engineering, University of Wisconsin, Madison, WI 53706-1687

36. R. W. Conn, Mechanical, Aerospace, and Nuclear Engineering Department, 6291 Boelter Hall, University of California, Los Angeles, CA 90024-1597

37. N. A. Davies, Director, Office of Fusion Energy, Office of Energy Research, ER-50 Germantown, Department of Energy, Washington, DC 20585

38. S. O. Dean, Fusion Power Associates, Inc., 2 Professional Drive, Suite 248, Gaithersburg, MD 20879

39. J. Doane, General Atomics, Fusion Group, P. O. Box 85608, San Diego, CA 92186-9784

40. H. K. Forsen, Bechtel Group, Inc., Research Engineering, P.O. Box 3965, San Francisco, CA 94119

41. R. Freeman, General Atomics, Fusion Group, P. O. Box 85608, San Diego, CA 92186-9784

42. T. V. George, Plasma Technologies Branch, Division of Development and Technology, Office of Fusion Energy, Office of Energy Research, ER-531 Germantown, Department of Energy, Washington, DC 20585 
43. R. W. Gould, Department of Applied Physics, California Institute of Technology, Pasadena, CA 91125

44. R. A. Gross, Plasma Research Laboratory, Columbia University, New York, NY 10027

45. R. J. Hawryluk, Princeton Plasma Physics Laboratory, P.O. Box 451, Princeton, NJ 08543

46. P. C. Liewer, MS 138-208, Jet Propulsion Laboratory, 4800 Oak Grove Drive, Pasadena, CA 91109

47. W. Lindquist, Lawrence Livermore National Laboratory, P. O. Box 808 (L-644), Livermore, CA 94551-9900

48. D. M. Meade, Princeton Plasma Physics Laboratory, P.O. Box 451, Princeton, NJ 08543

49. M. Mikowski, ITER c/o Max-Planck Institut für Plasmaphysik, Boltzmannstr.2, D-85748 Garching bei München, Germany

50. C. Moeller, Fusion Group, P. O. Box 85608, San Diego, CA 92186-9784

51. W. Nevins, Lawrence Livermore National Laboratory, P. O. Box 808 (L-644), Livermore, CA $94551-9900$

52. E. Oktay, Division of Confinement Systems, Office of Fusion Energy, Office of Energy Research, ER-55 Germantown, Department of Energy, Washington, DC 20585

53. R. Parker, ITER c/o Max-Planck Institut für Plasmaphysik, Bol nannstr.2, D-85748 Garching bei München, Germany

54. D. Remsen, ITER c/o Max-Planck Institut für Plasmaphysik, Boltzmannstr.2, D-85748 Garching bei München, Germany

55. M. Roberts, International Programs, Office of Fusion Energy, Office of Energy Research, ER-52 Germantown, Department of Energy, Washington, DC 20585

56. M. Sawan, University of Wisconsin, Engineering Research Building, 1500 Johnson Drive, Madision, WI 53706-1687

57. G. R. Smith, Lawrence Livermore National Laboratory, P. O. Box 808 (L-630), Livermore, CA $94551-9900$

58. W. M. Stacey, School of Nuclear Engineering and Health Physics, Georgia Institute of Technology, Atlanta, GA 30332

59. H. S. Staten, Plasma Technologies Branch, Division of Development and Technology, Office of Fusion Energy, Office of Energy Research, ER-531 Germantown, Department of Energy, Washington, DC 20585

6. D. Steiner, Nuclear Engineering Department, NES Building, Tibbetts Avenue, Rensselaer Polytechnic Institute, Troy, NY 12181

61. R. Temkin, Massachusetts Institute of Technology, Plasma Fusion Center, 167 Albany Street, Room 186, Cambridge, MA 02139

62. K. I. Thomassen, L-637, Lawrence Livermore National Laboratory, P.O. Box 5511, Livermore, CA 94550

63. R. Varma, Physical Research Laboratory, Navrangpura, Ahmedabad 380009, India

64. R. Vernon, University of Wisconsin, University of Wisconsin, Engineering Research Building, 1500 Johnson Drive, Madision, WI 53706-1687

65. Bibliothek, Max-Planck Institut für Plasmaphysik, Boltzmannstrasse 2, D-85748 Garching, Germany

66. Bibliothek, Institut für Plasmaphysik, KFA Jülich GmbH, Postfach 1913, D-5170 Jülich, Germany

67. Bibliothek, KfK Karlsruhe GmbH, Postfach 3640, D-7500 Karlsruhe 1, Germany 
68. Bibliotheque, Centre de Recherches en Physique des Plasmas, Ecole Polytechnique Fédérale de Lausanne, 21 Avenue des Bains, $\mathrm{CH}-1007$ Lausanne, Switzerland

69. R. Aymar, CEN/Cadarache, Departement de Recherches sur la Fusion Contrôlée, F-13108 Saint-Paul-lez-Durance Cedex, France

70. Bibliothèque, CEN/Cadarache, F-13108 Saint-Paul-lez-Durance Cedex, France

71. Library, JET Joint Undertaking, Abingdon, Oxfordshire OX14 3EA, England

72. Library, FOM-Instituut voor Plasmafysica, Rijnhuizen, Edisonbaan 14, $3439 \mathrm{MN}$ Nieuwegein, The Netherlands

73. Library, National Institute for Fusion Science, Chikusa-ku, Nagoya 464-01, Japan

74. Library, International Centre for Theoretical Physics, P.O. Box 586, I-34100 Trieste, Italy

75. Library, Centro Richerche Energia Frascati, C.P. 65, I-00044 Frascati (Roma), Italy

76. Library, Plasma Physics Laboratory, Kyoto University, Gokasho, Uji, Kyoto 611, Japan

77. Plasma Research Laboratory, Australian National University, P.O. Box 4, Canberra, A.C.T. 2601, Australia

78. Library, Japan Atomic Energy Research Institute, Naka Fusion Research Establishment, 801-1 Mukoyama, Naka-machi, Naka-gun, Ibaraki-ken, Japan

79-109. Given distribution as shown in DOE/OSTI-4500-R75 under category UC-420, Magnetic Fusion Energy) 

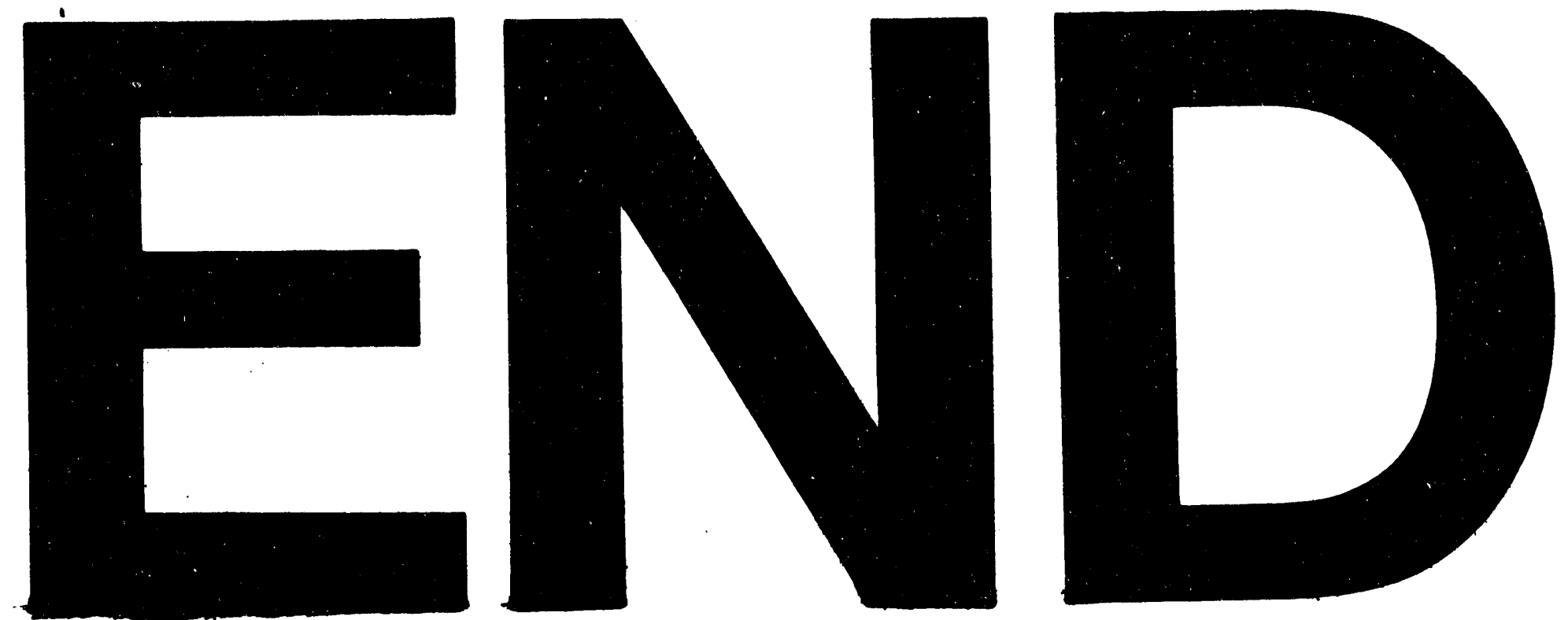

$\$$
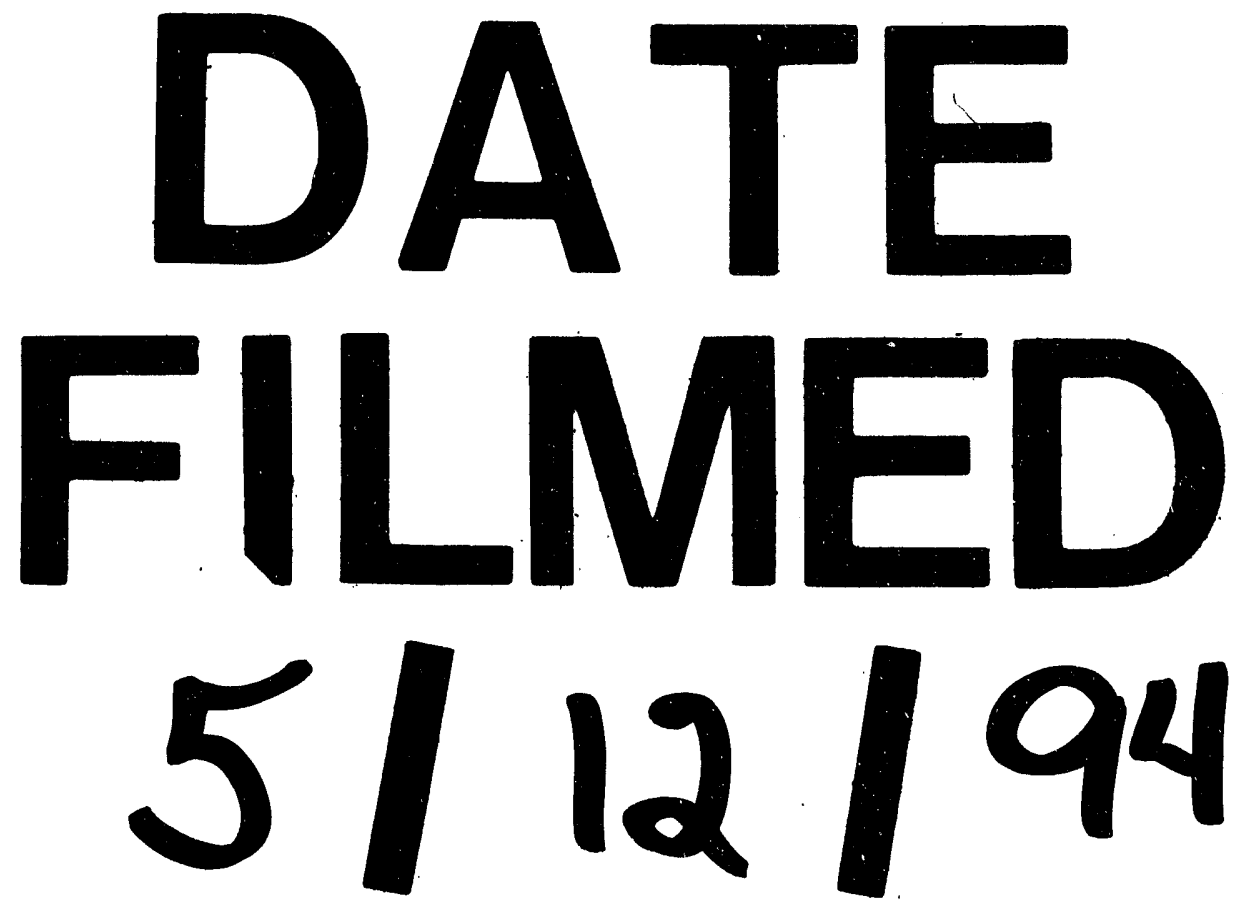
